\title{
Perbandingan Tingkat Stres pada Mahasiswa Angkatan 2018 dengan Angkatan 2015 Fakultas Kedokteran Universitas Baiturrahmah
}

\author{
Agusmar, $\mathrm{AY}^{1}$, Vani, $\mathrm{AT}^{2}$, Wahyuni, $\mathrm{Sri}^{3}$ \\ ${ }^{1}$ Mahasiswa Fakultas Kedokteran Universitas Baiturrahmah, Padang, Indonesia \\ E-mail : Adthitya1368@gmail.com \\ ${ }^{2}$ Bagian Histologi Fakultas Kedokteran Universitas Baiturrahmah, Padang, Indonesia \\ ${ }^{3}$ Dosen Fakultas Kedokteran, Universitas Baiturrahmah, Padang, Indonesia
}

\begin{abstract}
Abstrak
Latar belakang: Mahasiswa mengalami stres sebagai tuntutan kehidupan akademik yang harus mereka jalani. Mahasiswa yang mengalami stres akan mengalami dampak negatif yang akan mengganggu perkuliahan dan kinerja mereka serta berdampak buruk terhadap profesinya kelak sebagai seorang dokter. Tujuan: Penelitian ini bertujuan untuk mengetahui perbandingan tingkat stres pada mahasiswa angkatan 2018 dengan angkatan 2015 Fakultas Kedokteran Universitas Baiturahmah. Metode: Menggunakan metode analitik komparatif katagorik tidak berpasangan observasional dengan pendekatan cross-sectional. Sampel dalam penelitian ini adalah mahasiswa Fakultas Kedokteran Universitas Baiturrahmah angkatan 2015 dan angkatan 2018 yang berjumlah 80 orang. Data didapatkan dari jawaban responden atas kuesioner PSS-10. Analisa data menggunakan uji chisquare. Hasil: Dari angkatan 2015 paling banyak mengalami stres sedang (87,5\%), Angkatan 2018 paling banyak mengalami stres sedang $(60 \%)$ dan terdapat perbedaan tingkat stres pada mahasiswa angkatan 2018 dengan angkatan 2015 Fakultas Kedokteran Universitas Baiturahmah, dimana angkatan 2015 lebih tinggi dari angkatan 2018, p=0,020 ( $<<0,05)$. Kesimpulan: Angkatan 2015 dan angkatan 2018 terbanyak mengalami stres tingkat sedang dan stres pada angkatan 2015 lebih tinggi dari angkatan 2018
\end{abstract}

\section{Katakunci - Stres, Tingkat Stres, Mahasiswa, Stresor, PSS-10}

\section{Abstract}

Bacground: Stress in college students have negative impacts to their lectures and performance. Objective: The aim was to determine comparison of stress level in medical college of 2018 with 2015 in medical faculty of Baiturrahmah University. Method: This research was cross sectional study, observational unpaired categorical comparative analytics. The participants were 80 peoples. Stress was assessed by using Perceived Stress Scale (PSS-10). Data obtained was tabulated and analyzed using chi-square. Result: The medical college of 2015 had moderate stress (87.5\%), the medical college of 2018 had moderate stress (60\%) and there was a significant difference in stress level between the two groups, the medical college of 2015 was higher than the 2018, $p=$ 0.020 ( $p$ <0.05). Conclusion: the medical college of 2015 and the 2018 had moderate stress and stress in medical college of 2015 was higher than the 2018.

Keywords-Stress, Stress Level, College Student, Stressor, PSS-10 


\section{Pendahuluan}

Lazarus dan folkman menyatakan bahwa, stres merupakan hubungan antara individu dan lingkungan yang melampaui kemampuan dan membahayakan kesejahteraannya. ${ }^{1}$ Menurut Sarafino stres adalah kondisi yang disebabkan oleh interaksi antara individu dengan lingkungan, menimbulkan persepsi jarak antara tuntutantuntutan yang bersumber dari keadaan biologis, psikologis, dan sosial seseorang. ${ }^{2}$ Menurut Hans Selye Stres adalah suatu respon tubuh non spesifik terhadap tuntutan yang di terima individu dalam hidupnya. ${ }^{3}$

Mahasiswa adalah seseorang yang sedang menjalani pendidikan tinggi di perguruan tinggi. Mahasiswa mengalami stres sebagai tuntutan kehidupan akademik yang harus mereka jalani, seperti perubahan gaya belajar dari sekolah menengah ke perguruan tinggi, tugas-tugas perkuliahan, target pencapaian nilai, prestasi akademik dan problemproblem akademik lainnya. Faktor pencetus stres lainnya berhubungan dengan faktor personal seperti jauhnya mahasiswa dari orang tua dan saudara, faktor finansial, serta faktor interaksi dengan teman dan lingkungan baru. ${ }^{4}$

Mahasiswa yang mengalami stres akan mengalami dampak negatif yang akan mengganggu perkuliahan serta menganggu kinerja mereka. Mahasiswa yang mengalami kondisi stres yang ekstrem atau depresi membutuhkan perhatian serius. Apabila mereka tidak mampu mengatasi stres selama pendidikan, terutama mahasiswa kedokteran, hal tersebut akan berdampak buruk terhadap dirinya pribadi dan profesinya kelak sebagai dokter. ${ }^{5}$

Penelitian Agung menyebutkan bahwa stres mahasiswa angkatan akhir tergolong sangat tinggi, sebanyak 97,0\%. Hal tersebut dikarenakan oleh faktor emosi dan kurangnya self efficacy. ${ }^{11}$ Penelitian Gamayanti menyebutkan bahwa stres pada mahasiswa angkatan akhir sebesar 69,39\%. ${ }^{12}$ Penelitian Hastuti menyebutkan bahwa prevalensi stres pada mahasiswa tingkat akhir sebesar $83,3 \% .^{13}$ Hasil penelitian ini sejalan dengan penelitian Ageng Pramudhita yang menyebutkan bahwa prevalensi stres mahasiswa tingkat akhir sebesar 50\%. ${ }^{14}$

Penelitian Rony di Riau mengemukakan hasil yang berbeda yaitu tingkat stres pada mahasiswa tingkat awal lebih tinggi dibandingkan dengan tingkat akhir dengan prevalesi 57,23\%. ${ }^{15}$ Hasil penelitian ini sejalan dengan penelitian Gita Augesti di Lampung dengan prevalensi sebesar 59,2\%. Terdapat hubungan yang bermakna secara statistik antara tingkatan perkuliahan dan tingkatan stres, yaitu tingkat stres akan menurun seiring dengan meningkatnya tahun perkuliahan. $^{16}$

Berdasarkan latar belakang tersebut, dapat disimpulkan bahwa tingkat stres pada mahasiswa masih cukup tinggi terutama pada mahasiswa angkatan akhir dibandingkan dengan angkatan awal. Penelitian tentang perbedaan tingkat stres antara mahasiswa angkatan awal dan angkatan akhir di Fakultas Kedokteran Universitas Baiturrahmah juga belum pernah dilakukan sebelumnya. Oleh karena itu, peneliti ingin melakukan penelitian untuk mengetahui perbedaan tingkat stres pada mahasiswa angkatan 2018 dengan angkatan 2015 Fakultas Kedokteran Universitas Baiturrahmah.

\section{Metode Penelitian}

Penelitian ini merupakan penelitian Analitik Komparatif Kategorik tidak Berpasangan Observasional dengan menggunakan pendekatan cross sectional. Populasi penelitian ini adalah mahasiswa angkatan 2015 dan 2018 Fakultas Kedokteran Universitas Baiturrahmah. Subjek dalam penelitian ini diambil secara Simple Random Sampling. Data pada penelitian ini diambil menggunakan data primer yaitu kuesioner. 
Analisa data yang dilakukan setelah pengelolahan data hasil penelitian adalah Analisa Univariat dan Analisa Bivariat. Data diproses dan diolah dengan bantuan program komputer yaitu SPSS V.24

\section{HASIL}

TABEL 1. Distribusi FrekUENSI STRES MAHASISWA ANGKaTAN 2015 FAKULTAS KEDOKTERAN UNIVERSITAS BAITURRAHMAH TAHUN 2018

\begin{tabular}{lll}
\hline Tingkat Stres & $\boldsymbol{n}$ & $\mathbf{\%}$ \\
\hline Ringan & 4 & 10.0 \\
Sedang & 35 & 87.5 \\
Berat & 1 & 2.5 \\
\hline Jumlah & 40 & 100 \\
\hline
\end{tabular}

Berdasarkan tabel 1 didapatkan hasil angkatan 2015 di Fakultas Kedokteran Universitas Baiturrahmah paling banyak mengalami stres sedang yaitu $87,5 \%$.

TABEL 2. DisTRIBUSI FREKUENSI STRES MaHASISWA ANGKatan 2018 FaKUlTaS KEDOKTERAN UNIVERSITAS BAITURRAHMAH TAHUN 2018

\begin{tabular}{lll}
\hline Tingkat Stres & $\boldsymbol{n}$ & \% \\
\hline Ringan & 12 & 30.0 \\
Sedang & 24 & 60.0 \\
Berat & 4 & 10.0 \\
\hline Jumlah & 40 & 100 \\
\hline
\end{tabular}

Berdasarkan tabel 2 didapatkan hasil angkatan 2018 di Fakultas Kedokteran Universitas Baiturrahmah paling banyak mengalami stres sedang yaitu $60 \%$.

Tabel 3. Perbedaan Tingkat Stres Pada MAHASISWA ANGKATAN 2018 DENGAN ANGKATAN 2015 FAKULTAS KEDOKTERAN UNIVERSITAS BAITURRAHMAH

\begin{tabular}{|c|c|c|c|c|c|c|}
\hline \multirow{3}{*}{$\begin{array}{l}\text { Tingkat } \\
\text { Stres }\end{array}$} & \multicolumn{4}{|c|}{ Angkatan Mahasiswa } & \multirow{2}{*}{\multicolumn{2}{|c|}{ Total }} \\
\hline & \multicolumn{2}{|c|}{2015} & \multicolumn{2}{|c|}{2018} & & \\
\hline & $n$ & $\%$ & $n$ & $\%$ & $n$ & $\%$ \\
\hline Ringan & 4 & 25 & 12 & 75 & 16 & 100 \\
\hline Sedang & 35 & 59,3 & 24 & 40,7 & 59 & 100 \\
\hline Berat & 1 & 20 & 4 & 80 & 5 & 100 \\
\hline Total & 40 & 50 & 40 & 50 & 80 & 100 \\
\hline $\mathrm{P}$ value & & & 0,0 & & & \\
\hline
\end{tabular}

Berdasarkan tabel 3 diperoleh hasil stres sedang lebih banyak terjadi pada mahasiswa angkatan 2015 yaitu $(59,3 \%)$ dibandingkan dengan angkatan 2018 yaitu (40,7\%). Hasil uji statistic (chi-square) diperoleh nilai $\mathrm{p}=0,020(\mathrm{p}<0,05)$, maka dapat disimpulkan bahwa terdapat perbedaan tingkat stres pada mahasiswa angkatan 2018 dengan angkatan 2015 Fakultas Kedokteran Universitas Baiturrahmah, dimana angkatan 2015 lebih tinggi dari angkatan 2018.

\section{Pembahasan}

\section{A. Gambaran Tingkat Stres Mahasiswa Angkatan 2015}

Berdasarkan penelitian diperoleh hasil mahasiswa angkatan 2015 di Fakultas Kedokteran Universitas Baiturrahmah paling banyak mengalami stres sedang sebanyak $87,5 \%$.

Hasil penelitian ini sejalan dengan penelitian yang dilakukan Patil di India bahwa mahasiswa tingkat akhir mengalami stres ringan sebanyak 34,54\%, stres sedang sebanyak $40 \%$ dan stres berat sebanyak $25,45 \% .{ }^{17}$ Penelitian Gamayanti menemukan hasil yang sama dimana $12,24 \%$ mahasiswa tingkat akhir mengalami stres berat, 69,39\% mahasiswa mengalami stres sedang, dan $18,37 \%$ mahasiswa mengalami stres ringan. ${ }^{18}$

Beberapa faktor yang menjadi penyebab stres pada mahasiswa angkatan akhir adalah kegagalan dalam penyesuaian diri, penumpukan beban kuliah, faktor finansial, kurangnya Self-Efficacy, hubungan dengan teman, pasangan, career dimasa depan, dan kurangnya manajemen waktu. ${ }^{19}$

\section{B. Gambaran Tingkat Stres Mahasiswa Angkatan 2018}

Berdasarkan penelitian diperoleh hasil mahasiswa angkatan 2018 di Fakultas Kedokteran Universitas Baiturrahmah mengalami stres sedang sebanyak $60 \%$ dan stres ringan sebanyak $30 \%$. 
Penelitian ini sejalan dengan penelitian Augesti dengan hasil sebanyak 13,4\% mahasiswa tingkat awal mengalami stres berat, 59,2\% mengalami stres sedang, dan $27,5 \%$ mengalami stres ringan. ${ }^{16}$ Penelitian Rony di Riau juga mengemukakan hasil yang sama yaitu $19,88 \%$ mengalami stres berat, $57,23 \%$ mengalami stres sedang, dan $22,89 \%$ mengalami stres ringan. ${ }^{15}$

Beberapa faktor yang menyebabkan stres pada mahasiswa angkatan awal adalah Adaptasi dari lingkungan sekolah ke lingkungan universitas, tempat tinggal yang jauh dari orang tua, dan lingkungan yang buruk. $^{21}$

\section{Perbedaan Tingkat Stres pada}

Mahasiswa Angkatan 2018 dengan Angkatan 2015 Fakultas Kedokteran Universitas

Baiturrahmah

Penelitian ini memperoleh hasil yang sesuai dengan hipotesis, yaitu terdapat perbedaan tingkat stres antara mahasiswa angkatan 2015 dan angkatan 2018 dengan tingkat stres mahasiswa angkatan 2015 lebih tinggi dibandingkan tingkat stres mahasiswa angkatan 2018.

Hasil penelitian ini sejalan dengan penelitian yang dilakukan Madhyastha bahwa 3,6\% mahasiswa tingkat akhir mengalami stres berat, $49,5 \%$ mahasiswa mengalami stres sedang, dan 45,9\% mahasiswa mengalami stres ringan. ${ }^{22}$ Penelitian Marbun di Riau juga mengemukakan hasil yang sama bahwa sebanyak 4,1\% mahasiswa tingkat akhir mengalami stres ringan, sebanyak $91,8 \%$ mengalami stres sedang, dan sebanyak $4,1 \%$ mengalami stres berat. $^{23}$ Penelitian yang sama juga dilakukan oleh Amiruddin bahwa 37,3\% mahasiswa angkatan akhir mengalami stres ringan, 38,7\% mengalami stres sedang, dan $24,0 \%$ mengalami stres berat. ${ }^{24}$

Kemampuan adaptasi individu terhadap stres terdiri dari adaptasi fisiologis dan adaptasi psikologis. ${ }^{25}$ Stres pada mahasiswa angkatan 2015 Fakultas Kedokteran Universitas
Baiturrahmah diduga terjadi karena kegagalan adaptasi fisiologis mahasiswa pada tahap melawan (Stage of Resistance).

\section{KESIMPUlan DAN SARAN}

Pada penelitian ini didapatkan perbedaan tingkat stres pada mahasiswa angkatan 2018 dengan angkatan 2015 Fakultas Kedokteran Universitas Baiturrahmah, dimana angkatan 2015 lebih tinggi daripada angkatan 2018. $\mathrm{P}=0,020(\mathrm{p}<0,05)$.

\section{Daftar Pustaka}

1. Lazarus R, Folkman S. Stres, Apprisal, and Coping. New York: Springer Publisher Company; 1984.

2. Sarafino EP, Smith TW. Health Psychology. 7th ed. united states of

3. Selye H. Stress without Distress. 1st ed. Philadelpia: J.B Lippincott Company; 1976.america: wiley; 2011.

4. Santrock J. Adolescece: Perkembangan Remaja Edisi Keenam. 6th ed. (Shinto B, Saragih S, eds.). Jakarta: Erlangga; 2003.

5. Nandamuri PP, Ch G. Sources of Academic Stress - A Study on Management Students. J Manag Sci. 2011;1(2):31-42.

6. Marjani A, Gharavi A, Jahanshahi M, Vahidirad A, Alizadeh F. Stress among Medical Students of Gourgan (South East of Caspian Sea), Iran. Kathmandu Univ Med J. 2008;6(3):421-425.

7. Firth C. Emotional Distress in Junior Hospital Doctors. Br Med J. 2004;295(6):533.

8. Saipanish R. Stres among medical students in a Thai Medical School. Med teach. 2003;25(6):506.

9. Sherina M, Rampal L, Kaneson N. Psychological stress among undergraduate medical students. Malaysia Med J. 2004;59(11):207.

10. Al-Dabal B, Koura M, Rasheed P, Al-Sowielem L, Makki S. A comparative study of perceived stress among female medical and non-medical university students in Dammam, Saudi Arabia. Sultan Qaboos Univ Med J. 2010;10(2):231-240.

11. Agung G, Budiani M. Hubungan Kecerdasan Emosi dan Self Efficacy dengan Tingkat Stres Mahasiswa yang sedang Mengerjakan Skripsi. Penelit Psikol. 2013;1(2):1-5.

12. Gamayanti W, Syafei I. Self Disclosure dan Tingkat Stres pada Mahasiswa yang sedang Mengerjakan Skripsi. 2018;5(1984):115-130. doi:10.15575/psy.v5i1.2282.

13. Hastuti R, Arumsari A. Pengaruh Terapi Hipnotis Lima Jari untuk Menurunkan Kecemasan pada Mahasiswa yang sedang 


\section{Heme, Vol I No 2}

July 2019

Menyusun Skripsi di Stikes Muhammadiyah Klaten. 2015;10(21):25-35.

14. Pramudhita A. Hubungan Dukungan Keluarga dengan Tingkat Kecemasan Mahasiswa Tingkat Akhir Menghadapi Skripsi Di Stikes 'Aisyiyah Yogyakarta. 2013. http://lib.unisayogya.ac.id.

15. Wahyudi R, Bebasari E, Nazriati E. Gambaran Tingkat Stres pada Mahasiswa Fakultas Kedokteran Universitas Riau Tahun Pertama. $J$ Ilmu Kedokt. 2015;9(2):107-113.

16. Augesti G, Lisiswanti R, Saputra O, Nisa K. Differences in stress level between first year and last year medical students in medical faculty of lampung. $\quad J \quad$ Major. 2015;4(4):50-56. juke.kedokteran.unila.ac.id.

17. Patil SK, Patkar US, Patkar KU. Comparision of Levels of Stress in Different Years of M . B . B . $\mathrm{S}$. Students in A Medical College - An Observational Study. 2016;3(6):1655-1657.

18. Gamayanti W, Syafei I. Self Disclosure dan Tingkat Stres pada Mahasiswa yang sedang Mengerjakan Skripsi. 2018;5(1984):115-130. doi:10.15575/psy.v5i1.2282.

19. Garg K, Agarwal M, Dalal PK. Stress among medical students : A cross - sectional study from a North Indian Medical University. Indian $J$ Psikiatri. 2019;59:502-504. doi:10.4103/psychiatry.IndianJPsychiatry.

20. Papadopoulus C, Ali N. Stress levels and their risk/protective factors among MSc Public Health students. J Pedagog Dev. 2013;3(2).

21. Madhyastha S, Latha K, Kamath A. Stress and coping among final year medical students. $J$ Psychol Med. 2014;15(2):74-80.

22. Marbun APS, Arneliwati, Amir Y. Faktor- faktor yang mempengaruhi stres mahasiswa program transfer keperawatan yang sedang menyusun skripsi. J Kedokt dan Kesehat. 2017;5(7):446459.

23. Amiruddin. Analisis faktor - faktor penyebab tingkat kejadian stres pada mahasiswa fakultas kedokteran universitas hasanuddin angkatan 2015. 2017.

24. Potter PA. Buku Ajar Fundamental Keperawatan: Konsep, Proses, Dan Praktik. Jakarta: EGC; 2005 